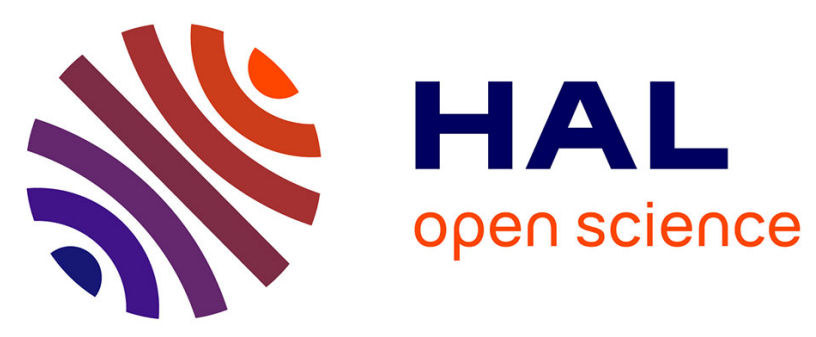

\title{
Interval From Initiation of Prasugrel to Coronary Angiography in Patients With Non-ST-Segment Elevation Myocardial Infarction
}

Johanne Silvain, Tomasz Rakowski, Benoit Lattuca, Zhenyu Liu, Leonardo Bolognese, Patrick Goldstein, Christian Hamm, Jean-Francois Tanguay, Jur ten Berg, Petr Widimsky, et al.

\section{To cite this version:}

Johanne Silvain, Tomasz Rakowski, Benoit Lattuca, Zhenyu Liu, Leonardo Bolognese, et al.. Interval From Initiation of Prasugrel to Coronary Angiography in Patients With Non-ST-Segment Elevation Myocardial Infarction. Journal of the American College of Cardiology, 2019, 73 (8), pp.906-914. 10.1016/j.jacc.2018.11.055 . hal-02150242

\section{HAL Id: hal-02150242 \\ https://hal.sorbonne-universite.fr/hal-02150242}

Submitted on 22 Oct 2021

HAL is a multi-disciplinary open access archive for the deposit and dissemination of scientific research documents, whether they are published or not. The documents may come from teaching and research institutions in France or abroad, or from public or private research centers.
L'archive ouverte pluridisciplinaire HAL, est destinée au dépôt et à la diffusion de documents scientifiques de niveau recherche, publiés ou non, émanant des établissements d'enseignement et de recherche français ou étrangers, des laboratoires publics ou privés.

\section{(ㄷ)(1) $\$$}

Distributed under a Creative Commons Attribution - NonCommerciall 4.0 International 


\section{Interval from Initiation of Prasugrel to Coronary Angiography in Patients with Non-ST Elevation Myocardial Infarction}

Johanne Silvain MD, $\mathrm{PhD}{ }^{1}$, Tomasz Rakowski MD ${ }^{2}$, Benoit Lattuca MD, ${ }^{1,3}$, Zhenyu Liu MD, ${ }^{4}$, Leonardo Bolognese MD, ${ }^{5}$, Patrick Goldstein MD, PhD ${ }^{6}$, Christian Hamm MD, ${ }^{7}$, JeanFrancois Tanguay MD,${ }^{8}$, Jur ten Berg MD, ${ }^{9}$, Petr Widimsky MD, ${ }^{10}$, Debra Miller ${ }^{11,}$ JeanJacques Portal ${ }^{12}$, Jean-Philippe Collet MD, $\mathrm{PhD}^{1}$, Eric Vicaut MD, $\mathrm{PhD}^{12}$, Gilles Montalescot $\mathrm{MD}, \mathrm{PhD} *^{1}$ and Dariusz Dudek MD ${ }^{2}$ for the ACCOAST investigators

1 Sorbonne University, ACTION Study Group, INSERM UMRS 1166, ICAN, Institut de Cardiologie, Hôpital Pitié-Salpêtrière (AP-HP), Paris, France

2 Institute of Cardiology, Jagiellonian University Medical College, Krakow, Poland 3 Service de Cardiologie, Centre Hospitalier Universitaire Nîmes, ACTION Study Group, Université Montpellier, France.

4 Department of Cardiology, Peking Union Medical College Hospital, Beijing, China

5 Cardiovascular and Neurological Department Azienda Ospedaliera, Arezzo, Italy.

6 SAMU and Emergency department. Lille University hospital/ 5900 Lille, France

7 Kerckhoff Heart and Thorax center, Bad Nauheim and Medical Clinic I, University of Giessen Germany.

8 Montreal Heart Institute, Montreal University, Quebec, Canada

9 Department of Cardiology, St. Antonius Hospital, Nieuwegein, the Netherlands

10 Third Medical Faculty of Charles University and University Hospital Royal Vineyards, Prague, Czech Repulic

11 RN, RCIS Eli Lilly and Company, Indianapolis, IN

12 Methodology and Statistical Unit, Centre Hospitalier Universitaire Lariboisière (ACTION Study Group, AP-HP, Université Paris 7), Paris, France.

Funding: The trial was sponsored by Daiichi Sankyo and Eli Lilly and was led by the ACTION Study Group at the Institute of Cardiology of Pitié-Salpêtrière Hospital.

DISCLOSURE: Johanne Silvain reports receiving research grants from, Brahms, DaiichiSankyo, Eli Lilly, INSERM, Fédération Française de Cardiologie and Société Française de Cardiologie Sanofi-Aventis; consultant fees from Astra Zeneca, Daiichi-Sankyo, The Medecine Company, Stentys and Eli Lilly and company; and lecture fees from Astra Zeneca, AAZ, Boehringer Ingelheim, Cordis, Daiichi-Sankyo, Eli Lilly and Company, and Iroko Cardio. Tomasz Rakowski has no conflict of interest to declare.

Benoit Lattuca reports receiving grants from Daiichi-Sankyo, Fédération Française de Cardiologie, Institute of Cardiometabolism and Nutrition; consultant fees from Daiichi-Sankyo and Eli-Lilly; lecture fees from Astrazeneca and Novartis

Zhenyu Liu reports receiving research grant to the institution from Astra Zeneca, and speaker fees from Abbott, Astra Zeneca, Bayer, BMS, Boehringer Ingelheim, Daiichi Sankyo, GlaxoSmithKline, Merck, MSD, Norvartis, Pfizer, Sanofi, Servier. Leonardo Bolognese reports receiving board membership from Eli Lilly and Company, Daiichi Sankyo, and consulting or lecture fees from Eli Lilly and Company, Daiichi Sankyo, Menarini Ind Farma, Abott, AstraZeneca, Iroko Cardio Int. 
Patrick Goldstein reports receiving speaker fees Astra Zeneca, Boehringer Ingelheim and consulting fees from Boehringer Ingelheim

Christian Hamm reports receiving consulting or speaker fees from Eli Lilly and Company, Abbott Vascular, Bayer, Boehringer Ingelheim, Boston Scientific, Cordis, Daiichi Sankyo, GlaxoSmithKline, Medtronic, Pfizer, Merck, Roche Diagnistics, Correvio, Sanofi-Aventis, AstraZeneca and The Medicines Comp and is a board member for AstraZeneca, Medtronic, and Boehringer Ingelheim.

Jean-Francois Tanguay reports research grants, advisory and speaker fees from Abbott Vascular, AstraZeneca, Bayer, and Reasearsh grant and consultation from Biosensors and Novartis. Jurrien M ten Berg reports Astrazeneca board membership, consultancy for Eli Lilly and Company, Astrazeneca and Merck, lecture fees for Eli Lilly and Company, and Astra Zeneca. Debra Miller is an employee and stock holder in Eli Lilly Company. Petr Widimsky reports receiving consulting and speaker fees from Eli Lilly and Daiichi Sankyo. Jean-Jacques Portal no conflict of interest to declare.

Jean-Philippe Collet has received research grants or honorarium from AstraZeneca, Bayer, Bristol-Myers Squibb, Daiichi-Sankyo, Eli-Lilly, Fédération Française de Cardiologie, Lead-Up, Medtronic, MSD, Sanofi-Aventis, WebMD all outside of the scope of this study.

Eric Vicaut reports receiving personal fees from Eli Lilly; consultancy from Pfizer, Sanofi, Lfb, Abbott, Fresenius, Medtronic, Hexacath, member of data safety monitoring board for Cerc, lecture fees from Novartis, and grants from BOEHRINGER and SANOFI.

Gilles Montalescot reports: research grants to the institution or consulting/lecture fees from Abbott Vascular, Accumetrics, AstraZeneca, Bayer, Biotronik, BMS, Boehringer-Ingelheim, Daiichi-Sankyo, Duke Institute, Eli Lilly and Company, Europa, Fédération Française de Cardiologie, Fondation de France, GSK, INSERM, Institut de France, Iroko, Lead-up, Menarini, Medtronic, Nanospheres, Novartis, Pfizer, Roche, Sanofi-Aventis, Stentys, Société Française de Cardiologie, Springer, The Medicines Company, The TIMI group, WebMD, and Wolters. Dariusz Dudek reports receiving consulting and lecture fees from Abbott, Adamed, Adyton Medical Polska, Abiomed Europe, AstraZeneca, Biotronik, Balton, Bayer, BBraun, BioMatrix, Boston Scientific, Boehringer Ing., Bracco, Bristol-Myers Squibb, Comesa Polska, Cordis, Cook, Covidien Polska Sp. z o. o., DRG MedTek, Eli Lilly, EuroCor, GE Hammermed, Healthcare, Glaxo, Inspire-MD, Iroko Cardio International, Medianet Sp. z o.o., Medtronic, Medicines Company, Meril Life Sciences, MSD, Orbus-Neich, Pfizer, Possis, ProCardia Medical, Promed, REVA Medical, Sanofi-Aventis, Siemens, Solvay, Stentys, St. Jude Medical, Terumo, Tyco, Volcano.

\section{Address for correspondence:}

Gilles Montalescot

ACTION Study Group

Institut de Cardiologie, Centre Hospitalier Universitaire Pitié-Salpêtrière

47 Boulevard de l'Hôpital

75013 Paris, France

Telephone: 33142163306

Fax: 33142162931

E-mail: gilles.montalescot@psl.aphp.fr

Twitter:@ActionCoeur | @ProfDDKardiolog 


\begin{abstract}
Background: In the ACCOAST trial, the prasugrel pretreatment strategy versus placebo was associated with excess bleeding complications and no improved ischemic outcome in non-ST segment elevation myocardial infarction (NSTEMI). Whether patients with the longest pretreatment duration had an ischemic benefit is unknown.

Objectives: This prespecified analysis of the ACCOAST trial aimed to assess the impact of pretreatment duration with prasugrel (time from randomization to angiography) on outcomes. Methods: Within the 4033 patients randomized in the ACCOAST trial, pretreatment duration was available in 4001 patients $(99.2 \%)$. The population of the trial was divided into quartiles of pretreatment duration (0.1-2.5 hours, 2.5-3.9 hours, 3.9-13.6 hours, $>13.6$ hours) with an evaluation of the primary efficacy endpoint of cardiovascular death, MI, stroke, urgent revascularization or GPIIb/IIIa bailout use. Secondary efficacy outcomes including cardiovascular death, MI, or stroke; all-cause death; stent thrombosis and safety outcomes (all CABG or non-CABG TIMI major bleeding) were also evaluated at 7 days.

Results: The primary efficacy outcome of cardiovascular death, MI, stroke, urgent revascularization or GPIIb/IIIa bailout use did not differ between the quartiles of pretreatment duration in the trial population ( $\mathrm{p}=0.17$ for interaction). None of the secondary efficacy outcomes were found to be dependent of pretreatment duration. The safety outcome of all CABG or non-CABG TIMI major bleedings did not differ between the quartiles of pretreatment duration $(\mathrm{p}=0.37$ for interaction).

Conclusions: In NSTEMI patients, the excess risk of bleeding and the absence of ischemic benefit were consistent across the quartiles of increasing duration of prasugrel pretreatment.

Clinical Trial Registration \#: NCT01015287.

Condensed Abstract: In the ACCOAST trial, the prasugrel pretreatment strategy versus placebo was not associated with improved ischemic outcome in non-ST segment elevation myocardial infarction. We evaluated whether this was related to a too short duration of pretreatment and assessed the impact of pretreatment duration with prasugrel on ischemic and bleeding outcomes. We found that neither the primary efficacy outcome of cardiovascular death, MI, stroke, urgent revascularization or GPIIb/IIIa bailout use nor the safety outcome of all CABG or non-CABG TIMI major bleeding differred between the quartiles of pretreatment duration $(p=0.17$ and $p=$ 0.37 for interaction respectively).
\end{abstract}

Keywords: Acute coronary syndrome, prasugrel, percutaneous coronary intervention, pretreatment, myocardial infarction
Abbreviations (in order of appearance)
$\mathrm{CABG}$ : coronary artery bypass grafting
PCI: percutaneous coronary intervention
NSTEMI : non-ST elevation myocardial infarction
NSTE-ACS : non-ST elevation acute coronary syndrome
STEMI : ST-segment elevation myocardial infarction
LD : first loading dose
BMI : body mass index 
MI : myocardial infarction

HR : Hazard-ratio

SD: standard deviation

CI : confidence intervals 


\section{Introduction}

Pre-treatment by $\mathrm{P}_{2} \mathrm{Y}_{12}$ inhibitors can delay coronary artery bypass grafting $(\mathrm{CABG})$ or increase unnecessarily the risk of bleeding in patients managed medically after undergoing an invasive strategy. Indeed, observational and randomized studies as well as meta-analyses have challenged the benefit of routine pre-treatment with clopidogrel in elective percutaneous coronary intervention (PCI) or non-ST elevation acute coronary syndrome (NSTE-ACS) showing no significant effect on mortality and a trend towards a decrease of ischemic endpoints but at the cost of an increase of major bleeding (1-8). The ACCOAST trial evaluated a strategy of pretreatment with prasugrel (versus placebo) in patients with non-ST elevation myocardial infarction (NSTEMI) (9) which did not provide an ischemic benefit but increased bleeding whatever the revascularization strategy chosen (10-12). In the protocol, the randomization was to take place as soon as possible, and the coronary angiography was to be performed within the first 48 hours of randomization, to reflect contemporary practice (13-16). The average delay between the first loading dose (LD) and the coronary angiography was 4.3 hours. One critiscim of the trial results was that this short delay may not have allowed pretreatment to be sufficiently active or protective although fast pharmacodynamics of the loading dose was reported both in ACCOAST and in previously published studies (17-21). The present analysis focuses on the duration of pretreatment within the 48 hours time frame to access the catheterization laboratory and see whether resuts differ in particular with longer duration of prasugrel pre-treatment.

\section{Methods}

\section{Study patients}

The ACCOAST trial randomized 4033 patients at a 1:1 ratio of active pretreatment with prasugrel or placebo in addition to aspirin and standard of care. The inclusion and exclusion criteria for the ACCOAST trial have been described previously $(9,10)$. Briefly, patients were 
eligible for inclusion if they had a diagnosis of a NSTEMI. Randomization was to take place as soon as possible after diagnosis and before the patients received a $\mathrm{LD}$ of any $\mathrm{P} 2 \mathrm{Y}_{12}$ antagonist. Patients had to be scheduled to undergo coronary angiography within 2 to $48 \mathrm{~h}$ from randomization. The ACCOAST study protocol pre-specified the present analysis of the impact of pretreatment duration on outcomes $(9,10)$. The ACCOAST population was therefore divided in quartiles according to the time from the first LD of treatment to the beginning of the coronary angiography. A similar analysis was performed in the PCI population, a subgroup of the ACCOAST trial limited to the patients who underwent PCI and presented in the appendix section.

Study procedures

Patients were randomly assigned to receive either prasugrel or a matching placebo once the patient was admitted with the diagnosis of NSTEMI to the study site. In the pre-treatment arm (patients that received a $30 \mathrm{mg}$ LD of prasugrel), an additional $30 \mathrm{mg}$ of prasugrel was given at the time of PCI once angiography confirmed the indication for PCI. In the no pretreatment arm the approved $60 \mathrm{mg}$ prasugrel LD was given after angiography only in patients undergoing PCI. If angiography revealed anatomy more appropriate for CABG or medical management, patients did not receive the second LD (30 mg) in the pretreatment arm or the $\mathrm{LD}(60 \mathrm{mg})$ in the no pretreatment arm. Thienopyridine use for patients medically managed or who needed CABG surgery was left to investigators' discretion. The first open-label maintenance dose of prasugrel was administered 18 to $24 \mathrm{~h}$ after PCI. Patients received a $10 \mathrm{mg}$ daily maintenance dose of prasugrel in combination with aspirin through the follow-up visit at 30 days. In patients who were 75 years of age or older and/or had body weight $<60 \mathrm{~kg}$, a $5 \mathrm{mg}$ daily maintenance dose of prasugrel was administered. 


\section{Study outcomes}

The primary composite endpoint was time to first occurrence of cardiovascular death, myocardial infarction (MI), stroke, urgent revascularization, or GP IIb/IIIa inhibitor bailout through 7 days from randomization. Secondary efficacy measures included cardiovascular death, MI, or stroke; all-cause death; stent thrombosis. Safety endpoints of TIMI major and minor bleeding were evaluated in terms of CABG surgery-related, or non-CABG surgery-related, and all bleeding.

\section{Statistical analysis}

The ACCOAST population was divided in quartiles according to the time from the first LD of treatment to the start of the coronary angiography (since missing data were very rare i.e. less than $1 \%$, no missing data replacement procedure was used). Patients characteristics were compared among the different quartiles by ANOVA for quantitative variables and Chi-square or Fisher's exact test for the qualitative parameters.

Hypothesis that the drug effect on Primary Efficacy or Safety Endpoints may be different according to the time from the first LD of treatment to the start of the coronary angiography has been tested by the interaction between factor treatment and time categorized by quartiles in a Cox model of survival analysis. In addition, difference between treatments for each quartile has been tested by log-rank test. Complementary analyses on efficacy and safety primary endpoints have been made using multivariate Cox model that included risk factors for the studied events (age $>75$, gender, body mass index $(\mathrm{BMI})>30$, diabetes, hypertension, previous PCI, previous

MI, baseline troponin and region of enrolment). All analyses have been made using SAS version 9.4 (from SAS Institute North Carolina USA)

\section{Results}




\section{Study patients}

Within the 4033 patients randomized in the ACCOAST trial, pretreatment duration was available in 4001 patients $(99.2 \%)$ of the global population. The quartiles of duration of pretreatment were 0.1-2.5 hours, 2.5-3.9 hours, 3.9-13.6 hours, >13.6 hours for the global population. The baseline characteristics of the four groups of patients are presented in Table $\mathbf{1}$. The main discrepancy between quartiles of pretreatment duration was the region of enrolment, with shorter pretreatment duration in Eastern Europe centers including Israel, and longer pretreatment duration for Western Europe and Canada. Differences of management strategy and antithrombotic therapy were also found and are displayed in Table 2. In comparison with the latest quartile of pretreatment (average time from the first dose to angiography of 23 hours), patients within the earliest quartile (average time from the first dose to angiography of 2.1 hours) had less medical management, less CABG and more PCI at 7 days. They were also mostly treated with unfractionated heparin $(77.4 \%)$ rather than with low molecular weight heparin (19\%) as compared with the latest quartile with a predominant use of low molecular weight heparin $(48.1 \%)$. For the PCI subgroup of 2770 patients, pretreatment duration was available in 2769 patients $(99.96 \%)$ and the quartiles of duration of pretreatment were quite similar to the global population (0.1-2.45 hours, 2.45-3.68 hours, 3.68-12.25 hours; $\geq 12.25$ hours). Procedural characteristics are described in Table 3. The main differences between the four groups were the higher rate of femoral approach (63.3\%) and bare metal stent implantation $(38.1 \%)$ found in the first quartile of pretreatment duration. Many of these variables were interrelated, reflecting in particular differences of practice across countries. Finally, we compared the patient's characteristics, medical management and procedural characteristics stratified by randomized arm within the four quartiles which were well balanced between the randomized arms. 


\section{Clinical outcomes}

The primary efficacy endpoint through 7 days from randomization is presented for each quartile of pretreatment in the Central Illustration for the global population ( $\mathrm{n}=4,001$ patients) and for the PCI population ( $\mathrm{n}=2769$ patients) in Online Figure 1. There was no interaction between prasugrel pretreatment and pretreatment duration for the primary efficacy endpoint in the global population $(\mathrm{p}=0.17)$. This finding was consistent across the secondary efficacy endpoints: $\mathrm{MI}$ ( $\mathrm{p}=0.37$ for interaction), stroke ( $\mathrm{p}=0.46$ for interaction) urgent revascularization ( $\mathrm{p}=0.29$ for interaction), GP IIb/IIIa in bail out ( $\mathrm{p}=0.28$ for interaction). Cardiovascular mortality could not be interpreted due to a very low rate of events. Full results are displayed in the appendix section table S1. The results concerning the PCI population showed a borderline significant interaction for the primary endpoint (Online Table 2), which must be interpreted with caution considering that pretreatment duration and PCI are two post-randomization variables. Few patients $(n=40)$ were censored as event-free prior to 7 days and the reasons why is described in Online Table 3.

The effect of prasugrel pretreatment on the safety outcomes of TIMI major bleeding through 7 days is reported by quartiles of pretreatment duration in Figure 1. There was a consitent increase in the rate of bleeding in all the quartiles for both the global and the PCI population. No interaction between groups was observed with consistent harm associated with pretreatment whatever the duration of pretreatment. The results were similar after multivariate analysis and no significant interaction was found between prasugrel pretreatment and pretreatment duration on the primary efficacy outcome at day $7(\mathrm{p}=0.13)$.

\section{Discussion}


The appropriate timing of $\mathrm{P} 2 \mathrm{Y}_{12}$ receptor inhibition in patients with non-ST segment elevation acute coronary syndrome (NSTE-ACS) remains debated, mostlly because of the lack of adequately sized randomized trial addressing this issue. Pretreatment in NSTE-ACS is defined by the administration of a $\mathrm{P} 2 \mathrm{Y}_{12}$ antagonist when an invasive strategy has been decided. It implies that the $\mathrm{P}_{2} \mathrm{Y}_{12}$ antagonist is given before coronary visualization, expecting an ischemic benefit while waiting for catheterization or during and after PCI when such revascularization is decided. Obviously, benefit is not expected from a treatment started before the angiography in patients needing rapid CABG surgery or if the final diagnosis is not a NSTE-ACS (e.g., pericarditis, aortic dissection, pulmonary embolism, hypertension, gastric ulcer, prancreatitis.). The PCI-CURE substudy (22) set the scene for pre-treament although it was performed with clopidogrel and did not fulfill the above definition since an invasive strategy was not required in CURE (23) and catheterization occurred only in $43 \%$ of patients. PCI-CURE was then a retrospective analysis of the highly selected $20 \%$ of patients who underwent PCI after a 10 -day waiting period on average. There is no other study of pretreatment in NSTE-ACS, and both CREDO (8) and PRAGUE-8 (6) were negative studies of pretreatment using clopidogrel and that included only elective PCI. In contrast, ACCOAST prospectively studied patients with an invasive strategy who could be pretreated before knowing their coronary status which was obtained within 48 hours. The benefit and the downsides of the pretreatment strategy can be fairly evaluated with this design, especially with the use of a more potent $\mathrm{P} 2 \mathrm{Y}_{12}$ antagonist such as prasugrel. The surprising negative results of ACCOAST were heavily debated. One recurrent critisicm of the results was that the pretreatment duration, altought peformed with prasugrel, was insufficient to allow $\mathrm{P} 2 \mathrm{Y}_{12}$ inhibition to be effective since the waiting period was considered by many to be too short (on average 4 hours). However, the 48-hour time window likely reflects 
current practice and accepting these critics we should expect an ischemic benefit in patients wih the longest pretreatment duration (1-2 days).

The present results do not support a duration-related benefit of prasugrel pretreatment. The results can be summarized as follows (Central Illustration): 1/ The hypothesis that longer pretreatment duration would have modified the results of the ACCOAST trial is not suggested by our analysis not even for the PCI population 2/ The safety issue with pretreatment was consistent across all four quartiles and confirms the drug was effective in all four groups. Of interest, patients within the shortest quartile of pretreatment duration which were given prasugrel 30mg within an average time of 2 hours before the angiography still had a significant increase in major bleeding events as compared with patients who received the loading dose after the angiography, indicating that there was sufficient platelet inhibition to increase bleeding. 3/ Patients of the first quartile with very rapid intervention may have been at higher risk and did not benefit from pretreatment. They actually had worse ischemic outcomes with pretreatment, with a borderline significant interaction in the PCI subgroup. However, this finding may be due to differences in baseline characteristics and the management used, or to the utilization of post-randomization variables (PCI and pretreatment duration) and we therefore cannot rule out the play of chance despite the multivariate analysis we performed.

In the 2015 ESC Guidelines for the management of NSTE-ACS (24), experts stated that as the optimal timing of ticagrelor or clopidogrel administration in NSTE-ACS patients scheduled for an invasive strategy had not been investigated, no recommendation for or against pretreatment with these agents could be formulated. In the recent 2018 ESC/EACTS guidelines on myocardial revascularization (25), although no additional trial on pretreatment was performed in the interval, expert recommended to pretreat NSTE-ACS patients undergoing 
invasive management with ticagrelor or clopidogrel (if ticagrelor is not an option) as soon as the diagnosis is established (Class IIa) on the basis that pretreatment was authorized in the PLATO trial (26), which is true given the fact that all patients were pretreated. However, it has to be specified that it was not a trial of pretreatment versus non-pretreatment, and as they cannot provide any data for this statement the level of evidence $\mathrm{C}$ was given. In fact, because of the design of the PLATO trial a dedicated study, albeit only pharmacodynamic, was conducted to support the use of ticagrelor after defining coronary anatomy (27). The available randomized data regrouped in a meta-analysis only support the utilization of pretreatment in STEMI patients, where pretreatment appears to improve coronary reperfusion before PCI, and reduce major cardiac adverse events, MI and bail-out GPI use without increase of major bleeding (28), whereas no benefit was found in the clinical setting of NSTE-ACS with a significant excess of major bleeding whether an invasive strategy was performed or not (4-5). We believe that such recommendations are more based on international experts' opinions and local practice than evidence-based medicine. The current North American guidelines are more cautious and do not recommend $\mathrm{P}_{2} \mathrm{Y}_{12}$ inhibitor pre-treatment in NTE-ACS; they simply refer to how the trials were actually performed (1).

This study has limitations. First this is pre-specified analysis has the inherent limitations of multiple testing. Second dividing the population in quartiles translated into a loss of power to show significant differences. However, we believe that the nature of the source data generated from a double-blind randomized trial and the large sample population would have been sufficient to show a significant difference or at least a clear trend if the tested hypothesis was true. Finally, we cannot exclude the play of chance for the borderline significant interaction found in PCI patients considering this type of subgroup analysis. In conclusion, in NSTEMI patients managed 
invasively, a longer duration of prasugrel pre-treament over a period of 48 hours before catheterization has no impact on ischemic outcomes. Thus, the present work refutes the hypothesis that insufficient time was given to prasugrel to provide an ischemic benefit and it confirms the main results of the ACCOAST trial including the bleeding excess that occurred whatever the duration of pretreatment. 


\section{Clinical Perspectives}

Competency in Patient Care and Procedural Skills: In patients with non-ST segment elevation acute coronary syndrome (NSTE-ACS), addition of the P2Y12 inhibitor, prasugrel, to aspirin and anticoagulation increases major bleeding without ameliorating ischemic risk irrespective of the interval between administration and coronary angiography. One explanation for this lack of benefit may be the heterogeneous mechanisms responsible for the acute syndrome and multiplicity of treatment strategies employed in this population.

Translational Outlook: Additional studies are needed to compare the safety and efficacy of fixed pretreatment regimens with administration of a rapidly acting P2Y12 inhibitor after determination of coronary pathoanatomy in patients with NSTE-ACS. 


\section{References}

1. Amsterdam EA, Wenger NK, Brindis RG et al. 2014 AHA/ACC Guideline for the Management of Patients with Non-ST-Elevation Acute Coronary Syndromes: a report of the American College of Cardiology/American Heart Association Task Force on Practice Guidelines. J Am Coll Cardiol. 2014 Dec 23;64(24):e139-e228. doi:

10.1016/j.jacc.2014.09.017. Epub 2014 Sep 23.

2. Ndrepepa G, Neumann FJ, Deliargyris EN. Bivalirudin versus heparin plus a glycoprotein IIb/IIIa inhibitor in patients with non-ST-segment myocardial infarction undergoing percutaneous coronary intervention after clopidogrel pretreatment: pooled analysis from the ACUITY and ISAR-REACT 4 trials. Circ Cardiovasc Interv 2012;5:705-12.

3. Lincoff AM, Steinhubl SR, Manoukian SV, et al. Influence of timing of clopidogrel treatment on the efficacy and safety of bivalirudin in patients with non-ST-segment elevation acute coronary syndromes undergoing percutaneous coronary intervention: an analysis of the ACUITY (Acute Catheterization and Urgent Intervention Triage strategY) trial. JACC Cardiovasc Interv. 2008;1:639-48.

4. Bellemain-Appaix A, O'Connor SA, Silvain J, et al. Association of clopidogrel pretreatment with mortality, cardiovascular events, and major bleeding among patients undergoing percutaneous coronary intervention: a systematic review and meta-analysis. JAMA 2012;308:2507-16.

5. Bellemain-Appaix A, Kerneis M, O'Connor SA, et al. Reappraisal of thienopyridine pretreatment in patients with non-ST elevation acute coronary syndrome: a systematic review and meta-analysis. BMJ. 2014 Oct 24;349:g6269. 
6. Widimsky P, Motovska Z, Simek S et al. Clopidogrel pre-treatment in stable angina: for all patients $>6 \mathrm{~h}$ before elective coronary angiography or only for angiographically selected patients a few minutes before PCI? A randomized multicentre trial PRAGUE-8. Eur Heart J 2008;29:1495-503.

7. Capodanno D, Angiolillo DJ. Pretreatment with antiplatelet drugs in invasively managed patients with coronary artery disease in the contemporary era: review of the evidence and practice guidelines. Circ Cardiovasc Interv. 2015 Mar;8(3):e002301.

8. Steinhubl SR, Berger PB, Mann JT 3rd, EJ et al. CREDO Investigators. Clopidogrel for the Reduction of Events During Observation. Early and sustained dual oral antiplatelet therapy following percutaneous coronary intervention: a randomized controlled trial. JAMA. 2002 Nov 20;288(19):2411-20. Erratum in: JAMA. 2003 Feb 26;289(8):987.

9. Montalescot G, Bolognese L, Dudek D, et al. A comparison of prasugrel at the time of percutaneous coronary intervention or as pretreatment at the time of diagnosis in patients with non-ST-segment elevation myocardial infarction: design and rationale for the ACCOAST study Am Heart J 2011;161:650-656.e1.

10. Montalescot G, Bolognese L, Dudek D et al. Pretreatment with prasugrel in non-STsegment elevation acute coronary syndromes. N Engl J Med. 2013 Sep 12;369(11):9991010.

11. Dudek D, Dziewierz A, Widimsky P et al. Impact of prasugrel pretreatment and timing of coronary artery bypass grafting on clinical outcomes of patients with non-ST-segment elevation myocardial infarction: From the A Comparison of Prasugrel at PCI or Time of Diagnosis of Non-ST-Elevation Myocardial Infarction (ACCOAST) study. Am Heart J. 2015 Nov;170(5):1025-1032.e2. 
12. Montalescot G, Collet JP, Ecollan P et al. Effect of prasugrel pre-treatment strategy in patients undergoing percutaneous coronary intervention for NSTEMI: the ACCOASTPCI study. J Am Coll Cardiol. 2014 Dec 23;64(24):2563-2571.

13. Mehta SR, Granger CB, Boden WE, et al. Early versus delayed invasive intervention in acute coronary syndromes. N Engl J Med 2009;360:2165-75.

14. Montalescot G, Cayla G, Collet JP, et al. Immediate vs delayed intervention for acute coronary syndromes: a randomized clinical trial. JAMA 2009;302:947-54.

15. Sorajja P,Gersh BJ, Cox DA, et al. Impact of delay to angioplasty in patients with acute coronary syndromes undergoing invasive management analysis from the ACUITY (Acute Catheterization and Urgent Intervention Triage strategY) trial. J Am Coll Cardiol 2010;55:1416-24.

16. Katritsis DG, Siontis GC, Kastrati A, et al. Optimal timing of coronary angiography and potential intervention in non-ST-elevation acute coronary syndromes. Eur Heart J 2011;32:32-40.

17. Collet JP, Silvain J, Bellemain-Appaix A et al. Pretreatment with P2Y12 inhibitors in non-ST-Segment-elevation acute coronary syndrome: an outdated and harmful strategy. Circulation. 2014 Nov 18;130(21):1904-14.

18. Wiviott SD, Trenk D, Frelinger AL, et al. Prasugrel compared with high loading- and maintenance-dose clopidogrel in patients with planned percutaneous coronary intervention: the Prasugrel in Comparison to Clopidogrel for the Inhibition of Platelet Activation and Aggregation-Thrombolysis in Myocardial Infarction 44 trial. Circulation. 2007;116:2923-32. 
19. Montalescot G, Sideris G, Cohen R, et al. Prasugrel compared with high-dose clopidogrel in acute coronary syndrome. The randomised, double-blind ACAPULCO study.Thromb Haemost 2010;103:213-23.

20. Jernberg T, Payne CD, Winters KJ et al. Prasugrel achieves greater inhibition of platelet aggregation and a lower rate of non-responders compared with clopidogrel in aspirintreated patients with stable coronary artery disease. Eur Heart J. 2006 May;27(10):116673. Epub 2006 Apr 18.

21. Wallentin L, Varenhorst C, James S et al. Prasugrel achieves greater and faster P2Y12receptor-mediated platelet inhibition than clopidogrel due to more efficient generation of its active metabolite in aspirin-treated patients with coronary artery disease. Eur Heart J. 2008 Jan;29(1):21-30.

22. Mehta SR, Yusuf S, Peters RJ et al. Clopidogrel in Unstable angina to prevent Recurrent Events trial (CURE) Investigators. Effects of pretreatment with clopidogrel and aspirin followed by long-term therapy in patients undergoing percutaneous coronary intervention: the PCI-CURE study. Lancet. 2001;358:527-533.

23. Yusuf S, Mehta SR, Zhao F et al. Clopidogrel in Unstable angina to prevent Recurrent Events Trial Investigators. Early and late effects of clopidogrel in patients with acute coronary syndromes. Circulation. 2003;107:966-972.

24. Roffi M, Patrono C, Collet JP et al. 2015 ESC Guidelines for the management of acute coronary syndromes in patients presenting without persistent ST-segment elevation: Task Force for the Management of Acute Coronary Syndromes in Patients Presenting without Persistent ST-Segment Elevation of the European Society of Cardiology (ESC). Eur Heart J. 2016 Jan 14;37(3):267-315. 
25. Neumann FJ, Sousa-Uva M, Ahlsson A, et al. 2018 ESC/EACTS Guidelines on myocardial revascularization.Eur Heart J. 2018 Aug 25. doi: 10.1093/eurheartj/ehy394.

26. Wallentin L, Becker RC, Budaj A et al. Ticagrelor versus clopidogrel in patients with acute coronary syndromes. N Engl J Med. 2009 Sep 10;361(11):1045-57.

27. Angiolillo DJ, Franchi F, Waksman R et al. Effects of Ticagrelor Versus Clopidogrel in Troponin-Negative Patients With Low-Risk ACS Undergoing Ad Hoc PCI. J Am Coll Cardiol. 2016 Feb 16;67(6):603-613. doi: 10.1016/j.jacc.2015.11.044.

28. Bellemain-Appaix A, Bégué C, Bhatt DL et al. The efficacy of early versus delayed P2Y12 inhibition in percutaneous coronary intervention for ST-elevation myocardial infarction: a systematic review and meta-analysis. EuroIntervention. 2018 May 20;14(1):78-85 


\section{Figure Legends:}

\section{Central Illustration: Pretreatment Duration in Non-ST Elevation Myocardial Infarction}

Patients. Primary Efficacy Endpoint (a composite of cardiovascular death, myocardial infarction, stroke, urgent revascularization or GPIIb/IIIa bailout) through 7 days in the global population of the ACCOAST trial. ${ }^{a} \mathrm{HR}$ is a $95 \%$ Cox hazards model with treatment. ${ }^{\mathrm{b}}$ Within subgroup p-value is from a 2-sided log-rank test. ${ }^{\mathrm{c} I n t e r a c t i o n ~} \mathrm{p}$-value is from a Cox propotional hazards model with treatment, subgroup, and treatment-by-subgroup interaction as fixed effects. Figure 1. The safety outcome of all CABG or non-CABG TIMI major bleeding through 7 days in the global population (upper figure) and (lower figure) with non-CABG TIMI major bleeding only. 
Table 1. Baseline characteristics of the global population, $n=4001$ patients.

\begin{tabular}{|c|c|c|c|c|c|}
\hline Pre Treatment Time & $\begin{array}{c}\text { Quartile } 1 \\
(0.1-2.5 \text { hr }) \\
(n=1008)\end{array}$ & $\begin{array}{c}\text { Quartile } 2 \\
(2.5-3.9 \text { hr }) \\
(n=997)\end{array}$ & $\begin{array}{c}\text { Quartile 3 } \\
(3.9-13.6 \mathrm{hr}) \\
(\mathrm{n}=996)\end{array}$ & $\begin{array}{c}\text { Quartile } 4 \\
(>13.6 \mathrm{hr}) \\
(\mathrm{n}=1000)\end{array}$ & p value \\
\hline
\end{tabular}




\begin{tabular}{|c|c|c|c|c|c|}
\hline \multicolumn{6}{|l|}{ Demographics (Mean \pm SD; n (\%)) } \\
\hline Age & $63.4 \pm 11$ & $63.8 \pm 11.3$ & $63.7 \pm 11.2$ & $63.7 \pm 11$ & 0.91 \\
\hline Elderly patients $\geq 75 \mathrm{yr}$ & $165(16.4 \%)$ & $177(17.8 \%)$ & $176(17.7 \%)$ & $188(18.8 \%)$ & 0.56 \\
\hline Male & $729(72.3 \%)$ & $721(72.3 \%)$ & $714(71.7 \%)$ & $737(73.7 \%)$ & 0.78 \\
\hline Weight in $\mathrm{Kg}$ & $82.4 \pm 15.9$ & $81.8 \pm 14.9$ & $80.9 \pm 14.5$ & $81.3 \pm 15.5$ & 0.17 \\
\hline Low body weight $<60 \mathrm{~kg}$ & $48(4.8 \%)$ & $47(4.7 \%)$ & $53(5.3 \%)$ & $57(5.7 \%)$ & 0.71 \\
\hline Body Mass Index & $28.1 \pm 4.7$ & $28.1 \pm 4.5$ & $27.9 \pm 4.4$ & $28.0 \pm 4.6$ & 0.69 \\
\hline \multicolumn{6}{|l|}{ Region of enrolment } \\
\hline Eastern Europe/Israel & $530(52.6 \%)$ & $486(48.7 \%)$ & $456(45.8 \%)$ & $210(21.0 \%)$ & \multirow{2}{*}{$<0.001 *$} \\
\hline Western Europe/Canada & $478(47.4 \%)$ & $511(51.3 \%)$ & $540(54.2 \%)$ & $790(79.0 \%)$ & \\
\hline \multicolumn{6}{|l|}{ Risk Factors } \\
\hline Diabetes mellitus & $202(20.0 \%)$ & $206(20.7 \%)$ & $193(19.4 \%)$ & $216(21.6 \%)$ & 0.65 \\
\hline Hypercholesterolemia & $438(43.5 \%)$ & $444(44.5 \%)$ & $449(45.1 \%)$ & $470(47.0 \%)$ & 0.44 \\
\hline Hypertension & $628(62.3 \%)$ & $634(63.6 \%)$ & $615(61.7 \%)$ & $607(60.7 \%)$ & 0.61 \\
\hline Current smoker & $344(34.2 \%)$ & $325(32.6 \%)$ & $356(35.8 \%)$ & $307(30.9 \%)$ & 0.11 \\
\hline Family history of CAD & $323(32.0 \%)$ & $358(35.9 \%)$ & $308(30.9 \%)$ & $343(34.3 \%)$ & 0.08 \\
\hline \multicolumn{6}{|l|}{ Past Cardiovascular disease } \\
\hline Previous PCI & $148(14.7 \%)$ & $161(16.1 \%)$ & $156(15.7 \%)$ & $188(18.8 \%)$ & 0.078 \\
\hline Previous CABG & $57(5.7 \%)$ & $49(4.9 \%)$ & $56(5.6 \%)$ & $49(4.9 \%)$ & 0.78 \\
\hline Previous MI & $130(12.9 \%)$ & $143(14.3 \%)$ & $142(14.3 \%)$ & $156(15.6 \%)$ & 0.39 \\
\hline \multicolumn{6}{|l|}{ NSTEMI severity } \\
\hline Ischemic changes on ECG & $570(57.2 \%)$ & $537(54.4 \%)$ & $516(52.1 \%)$ & $538(54.3 \%)$ & 0.16 \\
\hline Baseline Troponin level, $\geq 10 \times$ ULN & $508(50.7 \%)$ & $510(51.4 \%)$ & $464(46.8 \%)$ & $459(46.2 \%)$ & $0.041 *$ \\
\hline Grace Score $\geq 140$ & $232(23.4 \%)$ & $225(22.9 \%)$ & $207(21.3 \%)$ & $229(23.8 \%)$ & 0.59 \\
\hline Killip Class 1 & $972(96.4 \%)$ & $964(96.7 \%)$ & $962(96.6 \%)$ & $954(95.4 \%)$ & 0.40 \\
\hline
\end{tabular}

CABG means Coronary Artery Bypass Graft; CAD, Coronary Artery Disease; MI=Myocardial Infarction; PCI, Percutaneous Coronary Intervention. 
Table 2. Time delays, strategy and antithrombotic therapy within the four groups of the global population $n=4001$ patients. Values are given in Mean \pm SD or $n(\%)$.

\begin{tabular}{|c|c|c|c|c|c|}
\hline Pre Treatment Time & $\begin{array}{c}\text { Quartile } 1 \\
(0.1-2.5 \text { hr }) \\
(n=1008)\end{array}$ & $\begin{array}{c}\text { Quartile } 2 \\
(2.5-3.9 \text { hr }) \\
(n=997)\end{array}$ & $\begin{array}{c}\text { Quartile } 3 \\
(3.9-13.6 \mathrm{hr}) \\
(\mathrm{n}=996)\end{array}$ & $\begin{array}{c}\text { Quartile } 4 \\
(>13.6 \mathrm{hr}) \\
(\mathrm{n}=1000)\end{array}$ & p value \\
\hline \multicolumn{6}{|l|}{ Time delays (hrs) } \\
\hline Symptoms Onset to First Dose & $17.8 \pm 16.4$ & $20.2 \pm 29.5$ & $18.9 \pm 17.6$ & $21.5 \pm 70.9$ & 0.19 \\
\hline Time from First Dose to Angiography & $2.1 \pm 0.4$ & $3.10 \pm 0.4$ & $6.9 \pm 2.9$ & $23.3 \pm 43.5$ & $<0.001 *$ \\
\hline \multicolumn{6}{|l|}{ Treatment Sub-cohort at 7 Days } \\
\hline PCI Only & $760(75.4 \%)$ & $695(69.7 \%)$ & $677(68.0 \%)$ & $637(63.7 \%)$ & \multirow{4}{*}{$<0.001^{*}$} \\
\hline CABG Only & $49(4.9 \%)$ & $54(5.4 \%)$ & $58(5.8 \%)$ & $77(7.7 \%)$ & \\
\hline $\mathrm{PCI}+\mathrm{CABG}$ & $2(0.2 \%)$ & $4(0.4 \%)$ & $3(0.3 \%)$ & $2(0.2 \%)$ & \\
\hline Medical management & $197(19.5 \%)$ & $244(24.5 \%)$ & $258(25.9 \%)$ & $284(28.4 \%)$ & \\
\hline \multicolumn{6}{|l|}{ Antithrombotic therapy } \\
\hline Aspirin & $989(98.1 \%)$ & $972(97.5 \%)$ & $984(98.8 \%)$ & $985(98.5 \%)$ & 0.14 \\
\hline Unfractionated heparin & $509(77.4 \%)$ & $460(72.6 \%)$ & $446(65.8 \%)$ & $279(45.8 \%)$ & $<0.001 *$ \\
\hline Low-molecular-weight heparin & $125(19.0 \%)$ & $138(21.8 \%)$ & $208(30.7 \%)$ & $293(48.1 \%)$ & $<0.001 *$ \\
\hline Bivalirudin & $5(0.8 \%)$ & $9(1.4 \%)$ & $3(0.4 \%)$ & $2(0.3 \%)$ & 0.13 \\
\hline Multiple antithrombin therapy & $231(22.9 \%)$ & $248(24.9 \%)$ & $215(21.6 \%)$ & $299(29.9 \%)$ & $<0.001^{*}$ \\
\hline No antithrombin therapy & $119(11.8 \%)$ & $115(11.5 \%)$ & $103(10.3 \%)$ & $92(9.2 \%)$ & 0.21 \\
\hline GP IIb/IIIa inhibitor & $130(12.9 \%)$ & $123(12.3 \%)$ & $97(9.7 \%)$ & $107(10.7 \%)$ & 0.98 \\
\hline
\end{tabular}

CAD means Coronary Artery Disease; GP, Glycoprotein; MI=Myocardial Infarction; PCI, Percutaneous Coronary Intervention. 
Table 3. Procedural characteristics in the four groups of the PCI population. Values are given in Mean \pm SD or $\mathrm{n}(\%)$. Pretreatment quartile are slightly different from the global population as they only concern the PCI population $(n=2769)$ in this table.

\begin{tabular}{|c|c|c|c|c|c|}
\hline Pre Treatment Time & $\begin{array}{c}\text { Quartile } 1 \\
(0.1-2.45 \text { hr }) \\
(\mathrm{n}=691)\end{array}$ & $\begin{array}{c}\text { Quartile 2 } \\
(2.45-3.68 \text { hr }) \\
(\mathrm{n}=693)\end{array}$ & $\begin{array}{c}\text { Quartile 3 } \\
(3.68-12.25 \text { hr }) \\
(n=693)\end{array}$ & $\begin{array}{c}\text { Quartile } 4 \\
(\geq 12.25 \mathrm{hr}) \\
(\mathrm{n}=692)\end{array}$ & $p$ value \\
\hline \multicolumn{6}{|l|}{ PCI Procedure } \\
\hline Duration of PCI procedure (hrs) & $0.52 \pm 0.37$ & $0.49 \pm 0.35$ & $0.49 \pm 0.38$ & $0.50 \pm 0.39$ & 0.30 \\
\hline \multicolumn{6}{|l|}{ Arterial Sheath Location } \\
\hline Femoral & $637(63.3 \%)$ & $591(59.3 \%)$ & $523(52.7 \%)$ & $525(52.7 \%)$ & \multirow{2}{*}{$<0.001 *$} \\
\hline Radial or Brachial & $370(36.7 \%)$ & $406(40.7 \%)$ & $470(47.3 \%)$ & $472(47.3 \%)$ & \\
\hline \multicolumn{6}{|l|}{ Stents } \\
\hline Number of vessels treated & $1.3 \pm 0.6$ & $1.3 \pm 0.7$ & $1.3 \pm 0.7$ & $1.5 \pm 0.8$ & $<0.001 *$ \\
\hline 2 or more vessels treated & $159(20.8 \%)$ & $161(23.0 \%)$ & $165(24.3 \%)$ & $217(34.0 \%)$ & $<0.001 *$ \\
\hline Total number of stents & $1.2 \pm 0.6$ & $1.2 \pm 0.7$ & $1.2 \pm 0.6$ & $1.4 \pm 0.9$ & $<0.001 *$ \\
\hline No stent implanted & $45(5.9 \%)$ & $45(6.4 \%)$ & $34(5.0 \%)$ & $34(5.3 \%)$ & \multirow{4}{*}{$<0.001 *$} \\
\hline Bare metal stent only & $290(38.1 \%)$ & $264(37.8 \%)$ & $261(38.4 \%)$ & $172(26.9 \%)$ & \\
\hline Drug eluting stent only & $409(53.7 \%)$ & $364(52.1 \%)$ & $362(53.2 \%)$ & $399(62.4 \%)$ & \\
\hline Both BMS \& DES & $18(2.4 \%)$ & $26(3.7 \%)$ & $23(3.4 \%)$ & $34(5.3 \%)$ & \\
\hline
\end{tabular}

BMS means Bare Metal Stent; DES, Drug Eluting Stent; PCI, Percutaneous Coronary Intervention. 


\section{Primary Safety Endpoint}

(All TIMI Major Bleeding)

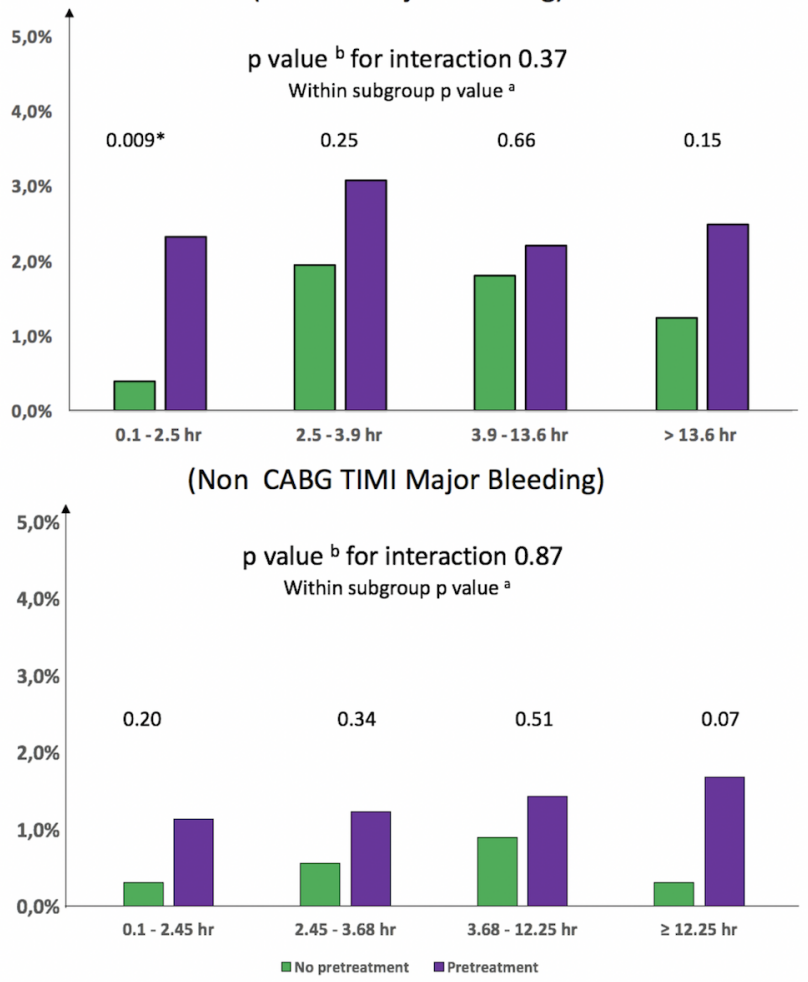

a Within subgroup $p$-value is from a two-sided log rank test

b Interaction p-value is from a Cox proportional hazards model with treatment, subgroup, and treatment-by-subgroup interaction as fixed effects 